\title{
BMJ Open Behaviour modification interventions to optimise red blood cell transfusion practices: a systematic review and meta- analysis
}

\author{
Lesley J J Soril, ${ }^{1,2}$ Thomas W Noseworthy, ${ }^{2}$ Laura E Dowsett,, ${ }^{1,2}$ \\ Katherine Memedovich, ${ }^{1,2}$ Hannah M Holitzki, ${ }^{1,2}$ Diane L Lorenzetti, ${ }^{1,2}$ \\ Henry Thomas Stelfox, ${ }^{1,2,3,4}$ David A Zygun, ${ }^{4,5}$ Fiona M Clement ${ }^{1,2}$
}

To cite: Soril LJJ,

Noseworthy TW, Dowsett LE, et al. Behaviour modification interventions to optimise red blood cell transfusion practices: a systematic review and meta-analysis. BMJ Open 2018;8:e019912. doi:10.1136/ bmjopen-2017-019912

- Prepublication history and additional material for this paper are available online. To view these files, please visit the journal online (http://dx.doi. org/10.1136/bmjopen-2017019912).

Received 3 0ctober 2017 Revised 8 February 2018 Accepted 20 March 2018

\section{Check for updates}

${ }^{1}$ Department of Community Health Sciences, University of Calgary, Calgary, Alberta, Canada

${ }^{2} 0$ 'Brien Institute for Public Health, The University of Calgary, Calgary, Alberta, Canada ${ }^{3}$ Department of Critical Care Medicine, Cumming School of Medicine, University of Calgary, Foothills Medical Centre, Calgary, Alberta, Canada ${ }^{4}$ Critical Care Strategic Clinical Network, Alberta Health Services, Edmonton, Alberta, Canada

${ }^{5}$ Department of Critical Care Medicine, Alberta Health Services and Faculty of Medicine and Dentistry, University of Alberta, Calgary, Alberta, Canada

Correspondence to Dr Fiona M Clement; fclement@ucalgary.ca

\section{ABSTRACT}

Objective To assess the impact of behaviour modification interventions to promote restrictive red blood cell (RBC) transfusion practices.

Design Systematic review and meta-analysis.

Setting, participants, interventions Seven electronic databases were searched to January 2018. Published randomised controlled trials (RCTs) or non-randomised studies examining an intervention to modify healthcare providers' RBC transfusion practice in any healthcare setting were included.

Primary and secondary outcomes The primary outcome was the proportion of patients transfused. Secondary outcomes included the proportion of inappropriate transfusions, RBC units transfused per patient, in-hospital mortality, length of stay (LOS), pretransfusion haemoglobin and healthcare costs. Meta-analysis was conducted using a random-effects model and meta-regression was performed in cases of heterogeneity. Publication bias was assessed by Begg's funnel plot.

Results Eighty-four low to moderate quality studies were included: 3 were RCTs and 81 were non-randomised studies. Thirty-one studies evaluated a single intervention, 44 examined a multimodal intervention. The comparator in all studies was standard of care or historical control. In 33 non-randomised studies, use of an intervention was associated with reduced odds of transfusion (OR 0.63 (95\% Cl 0.56 to 0.71$))$, odds of inappropriate transfusion (OR 0.46 (95\% Cl 0.36 to 0.59)), RBC units/patient weighted mean difference (WMD: -0.50 units $(95 \% \mathrm{Cl}$ -0.85 to -0.16$)$ ), LOS (WMD: -1.14 days $(95 \% \mathrm{Cl}-2.12$ to -0.16$))$ and pretransfusion haemoglobin $(-0.28 \mathrm{~g} / \mathrm{dL}$ $(95 \% \mathrm{Cl}-0.48$ to -0.08$))$. There was no difference in odds of mortality (OR 0.90 (95\% Cl 0.80 to 1.02)). Protocol/ algorithm and multimodal interventions were associated with the greatest decreases in the primary outcome. There was high heterogeneity among estimates and evidence for publication bias.

Conclusions The literature examining the impact of interventions on RBC transfusions is extensive, although most studies are non-randomised. Despite this, pooled analysis of 33 studies revealed improvement in the primary outcome. Future work needs to shift from asking, 'does it work?' to 'what works best and at what cost?' PROSPERO registration number CRD42015024757.
Strengths and limitations of this study

- In this systematic review and meta-analysis, 84 studies examining single and multimodal interventions to modify red blood cell transfusion practices were identified.

- This is the most comprehensive systematic review and the first meta-analysis of these interventions to date.

- Included studies were of low to moderate quality and almost all were designed as non-randomised, before and after studies.

- No studies examined the comparative effectiveness between behaviour modification interventions, nor the cost-effectiveness of interventions.

- There was significant statistical heterogeneity and evidence for publication bias.

\section{INTRODUCTION}

Blood transfusions are commonly administered as a life-saving therapy to restore haemoglobin levels among patients with severe anaemia. ${ }^{1-3}$ Blood and blood products, such as red blood cells (RBCs), are, however, scarce and expensive health resources that must be managed carefully to ensure judicious use and availability for those most in need of transfusions. ${ }^{4}$ Beyond blood conservation, transfusion safety and reducing the adverse events associated with transfusion must be considered. RBC transfusions have been associated with increased risk of infections, acute transfusion reactions and in certain cases, mortality. ${ }^{5-7}$ High-quality evidence has accumulated over the past two decades in support of reducing patient exposure to RBC transfusions, through the adoption of more restrictive RBC transfusion thresholds. ${ }^{8-12}$ A number of guidelines, such as those most recently released by the AABB (formerly the American Association of Blood 
Banks), ${ }^{13}$ have also recommended against transfusion if haemoglobin levels are above $7-8 \mathrm{~g} / \mathrm{dL}$ for most patients groups.

It is well documented that publication of such evidence alone is insufficient for affecting change ${ }^{14}$ Clinical practice is influenced by a myriad of social, cultural and environmental factors that are not necessarily considered in guidelines. ${ }^{15}$ Concerted change management efforts are, therefore, commonly undertaken to actively address these factors in order to implement recommended guidelines and achieve the desired practice change.

Interventions to specifically modify provider transfusion practices, such as education, audit and feedback, and computerised or paper order entry systems, have been described in prior studies. ${ }^{16-19}$ Previous systematic reviews have examined the impact of these interventions, alone or in combination, on transfusion practices for various blood components (eg, RBCs, fresh frozen plasma, platelets, cryoprecipitate). The findings of these syntheses report variability in outcomes-including a paucity of economic outcomes-and limitations in both the quality of evidence and breadth of interventions examined. ${ }^{16-18}$ With the exception of one systematic review published in 2015 that exclusively focused on the impacts of electronic decision support, ${ }^{18}$ these previous reviews are dated (last published in 2005). ${ }^{1617}$

Therefore, a de novo systematic review synthesising the current literature in this area, concentrating on all behaviour modification interventions targeting RBC transfusion practices, is useful as healthcare organisations respond to meet recent $\mathrm{RBC}$ transfusion guideline recommendations. The objective of this study was to determine the effectiveness of behaviour modification interventions that change RBC transfusion practices, specifically, the effects of interventions on the proportion of patients transfused, as well as patient and healthcare system outcomes.

\section{MATERIALS AND METHODS}

A systematic review of the published literature was completed in accordance with the Preferred Reporting Items for Systematic Reviews and Meta-Analyses (online supplementary file 1). ${ }^{20}$ The protocol for this systematic review is registered on the International Prospective Register for Systemic Reviews website (2015:CRD42015024757; online supplementary file 2). ${ }^{21}$

\section{Search strategy}

The electronic search strategy was developed by an Information Specialist (DLL). MEDLINE, PubMed, EMBASE, the Cochrane Central Registry of Controlled Trials, the Cumulative Index to Nursing and Allied Health, the Cochrane Database of Systematic Reviews and the Health Technology Assessment database were searched from inception to 12 January 2018. A sample search strategy is available in online supplementary file 3. Animal studies, case reports, comments, editorials and letters were excluded; no other limitations were applied. The references lists of identified systematic reviews were also hand searched for relevant articles not found through database searches.

\section{Selection of literature}

Studies were included if they: reported original data; examined the impact of a behaviour modification intervention on healthcare provider RBC transfusion practices; had a comparator group (eg, no intervention or another intervention) and were designed as either a randomised controlled trial (RCT) or non-randomised study. A non-randomised study involves the selection of groups each exposed to a different intervention without random assignment. ${ }^{22} 23$ Common non-randomised designs in behaviour modification studies include non-randomised trials (also referred to as between subjects or between group trials), time series studies, and uncontrolled and controlled before and after studies. ${ }^{23}{ }^{24}$ No fixed definition of a behaviour modification intervention was applied; thus, any definition used within the included studies was accepted. Included interventions were grouped using an inductive approach based on descriptors and labels provided from the studies themselves. Studies were excluded if they did not meet any of the above criteria, including if they only assessed transfusion of other blood products (ie, fresh frozen plasma, platelets, cryoprecipitate) and not in conjunction with RBCs. Detailed inclusion and exclusion criteria are provided in online supplementary file 4. Abstract and full-text screening were completed in duplicate (LJJS, LED, HMH, KM) and any disagreement was resolved through discussion and consensus, or through consultation with a third reviewer. Agreement between reviewers was calculated using a kappa statistic.

\section{Data extraction}

Data extraction was completed in duplicate using a standardised data extraction form (LJJS and KM). Data on publication date, country, healthcare setting, study design, follow-up period, type of intervention and comparator groups, intervention characteristics, RBC transfusion criteria, definition of an 'inappropriate' transfusion, number of patients treated in each group and the primary outcome of interest (the proportion of patients transfused) were extracted. Secondary outcomes, including the proportion of inappropriate transfusions, mean RBC units transfused per patient, in-hospital mortality, hospital length of stay (LOS), pretransfusion haemoglobin and changes in costs (eg, RBC unit costs) were also extracted where available.

\section{Quality assessment}

Risk of bias and quality assessments of included studies were completed in duplicate (LJJS and KM). The Cochrane Risk of Bias tool was used to evaluate the risk of bias among included RCTs. ${ }^{25}$ Quality of non-randomised studies were assessed using the Downs and Black Checklist. ${ }^{26}$ Typically scored out of 28 points, the Downs and Black Checklist was modified because several items do 


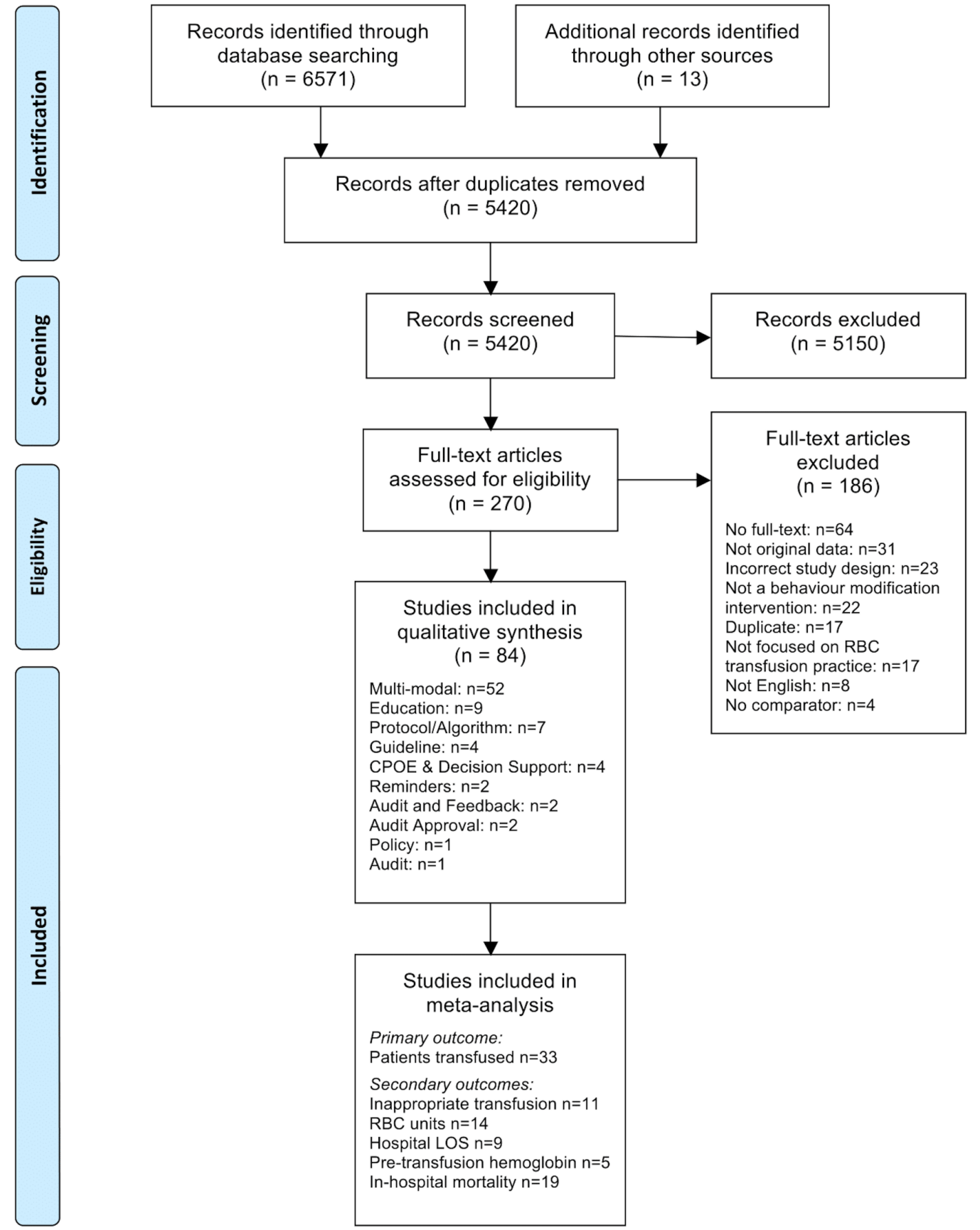

Figure 1 Preferred Reporting for Systematic Reviews and Meta-Analyses flow diagram of included studies. CPOE, computerised physician order entry; LOS, length of stay; RBC, red blood cell.

not apply to the non-randomised studies (eg, randomisation), thereby reducing the denominator to 22 for uncontrolled before and after studies, and 23 for controlled before and after and non-randomised trials.

\section{Data analysis}

Meta-analyses were conducted using a random-effects model. Pooled odds ratios (ORs) and weighted mean differences (WMDs), and their respective 95\% CIs were calculated for categorical and continuous outcomes, respectively. Stratified analyses by intervention type and study design were completed. Statistical heterogeneity was examined using both the $\mathrm{I}^{2}$ (percentage of total interstudy variation due to heterogeneity rather than chance) and $Q$ statistic $p$ value (test of homogeneity). An $\mathrm{I}^{2}$ greater than $50 \%$ was considered as evidence for significant heterogeneity. ${ }^{27}$ Random-effects meta-regression was performed with the year of publication, the number of interventions per study, having a multimodal intervention, a study setting in a single unit or clinical service, follow-up period (greater than 1year) and each of the identified intervention types as covariates. A regression coefficient with a $\mathrm{p}<0.10$ was considered a significant predictor of the primary outcome. Publication bias was examined using Begg's funnel plot and Egger's regression test. In the case of funnel plot asymmetry, the trim-andfill method was used to impute estimates from potentially suppressed publications. This method assumes that studies that do not demonstrate a desired effect (eg, decrease in 
proportion transfused) were not likely published.$^{28}$ All statistical analyses were completed using Stata/IC V.13.1.

\section{RESULTS}

\section{Search results}

The flow chart of included studies is provided in figure 1 . Five thousand four hundred and twenty unique abstracts were identified, of which 270 proceeded to full-text review. Thirteen additional relevant studies were identified through hand-searching. One hundred and eighty-six studies were excluded during full-text review, resulting in 84 articles included in the final analysis (Kappa $=87.0 \%$, $95 \%$ CI $80.8 \%$ to $93.1 \%$ ).

\section{Characteristics of included studies}

The characteristics of included studies are summarised in online supplementary file 5. The 84 included articles comprised 83 unique study populations, as two articles ${ }^{29} 30$ reported different outcomes for the same population. In addition, one article ${ }^{31}$ reported outcomes from two unique study studies; thus, the non-overlapping findings from both studies were included. The included studies were published between $1983^{32}$ and $2017,{ }^{33-38}$ with the majority of studies conducted in the USA $(n=50)$. Only three studies were RCTs (one cluster RCT, two randomised at the individual level) ${ }^{313940}$; the remaining 81 were non-randomised studies, specifically uncontrolled before and after $(n=74)^{29-31} 33-3638$ 41-106; controlled before and after $(n=2)^{107} 108$; interrupted time series $(\mathrm{n}=1)^{37}$ and non-randomised trial $(\mathrm{n}=4)^{32}$ 109-111 designs.

In all cases, an intervention was compared with either historical controls or standard of care. Most studies were conducted in a single acute care facility, often an academic hospital. Follow-up periods varied considerably from 2 weeks $^{82}$ to 6 years ${ }^{48}$ postintervention. Targeted populations included primarily physicians (eg, intensivists, anaesthesiologists, surgeons) ordering RBC transfusions, as well as medical trainees (eg, residents), other healthcare providers (eg, nurses) and hospital staff (eg, hospital laboratory and blood bank technologists) involved in the care of patients receiving transfusions. The unit of intervention was the individual healthcare provider, ward or unit, or institution (ie, not patients themselves).

\section{Types of interventions}

The effectiveness of either a single $(\mathrm{n}=32)$ or multiple interventions $(n=52)$ in combination (referred to as multimodal interventions) was evaluated. The following single intervention categories were identified: education sessions or materials $(n=9)^{40-86109}$, protocols or algorithms $(n=7)^{3990-95}$, guidelines $(n=4)^{87-89110}$, computerised physician order entry (CPOE) systems and decision support $(\mathrm{n}=4)^{31} 97-99$, reminders $(\mathrm{n}=2)^{100} 108$, audit and feedback $(n=2)^{101111}$, audit approval $(n=2)^{102} 103$, a clinical policy $(\mathrm{n}=1)^{96}$ and prospective audit of transfusion practices $(n=1) \cdot{ }^{37}$ Descriptions of each, along with examples from the included studies, are provided in table 1.

Multimodal interventions included between 2 and 5 strategies, applied concurrently or in sequence. Combinations of multimodal interventions are summarised in online supplementary file 6 . The interventions most commonly included in multimodal interventions were: education $(\mathrm{n}=38)^{29-3638414247-5153-5557-6062-6567-707274-77104105107}$, guidelines $(n=25)^{3134384244455053-56585961626465676972737576105107}$, and auditandfeedback $(\mathrm{n}=23) .3234363844464952-5557-606567-6971-7377$ Some multimodal interventions applied additional interventions not examined among the single intervention studies, including paper order forms $(\mathrm{n}=4),{ }^{61677173}$ financial incentives $(\mathrm{n}=1),{ }^{68}$ and physician checklists and order sets $(n=2){ }^{105} 106$

\section{Quality of included studies}

All three RCTs ${ }^{313940}$ incorporated study elements that were deemed to be of high, low and unclear risk of bias (online supplementary file 7). Due to the nature of the interventions, treatment allocation was not concealed, nor could the participants, personnel or outcome assessors be blinded; thus, risk of bias was consistently high in these areas. In contrast, risk of bias was low across all studies with respect to both attrition and reporting bias.

The majority of non-randomised studies $(n=63)$ were of moderate quality, where quality assessment scores ranged from 12 to $15 ; 12$ studies $^{32424447515256818892107109}$ were of low quality (scores from 0 to 11 ) and no studies were deemed to be of high quality (score $>17$ ) (online supplementary file 8 ). Most studies were found to have low scores due to poor reporting (Q1-Q10), particularly of the characteristics of the targeted population and distribution of principal confounders. External validity (Q11 and Q13) was moderate for most studies; however, Q12 (ie, subjects prepared to participate representative of the entire population) was deemed 'unable to determine' for all studies. The internal validity was low to moderate across studies (Q16-Q26). Adequate adjustment for confounding (Q25) and whether losses to follow-up were taken into account (Q26) were also deemed 'unable to determine' for all studies.

\section{Impact of behaviour modification interventions on RBC usage and patient outcomes}

A summary of the pooled analyses is provided in table 2. The primary outcome, the proportion of patients transfused, was reported in 33 studies. The pooled odds of a patient receiving a RBC transfusion was $0.70(95 \%$ CI 0.65 to $0.76 ; \mathrm{n}=33$ ) (figure 2; table 2). There was strong evidence of heterogeneity in this estimate $\left(\mathrm{I}^{2}=90.5 \%\right.$, Q-statistic $\mathrm{p}=0.00$ ), although this was not apparent on visual inspection as a number of studies crossed the null value. Sorting studies by year of publication showed that, with the exception of the two earliest studies, ${ }^{32}{ }^{89}$ the associated decrease in the odds of transfusion was fairly consistent over time (online supplementary file 9 ). 
Table 1 Categories of single and multimodal behaviour modification interventions

\section{Description of techniques}

\section{Examples from included studies}

Education

Educational materials or group sessions to disseminate:

(1) specific medical evidence, such as aetiology and pathophysiology of anaemia, indications for transfusion, risks of red blood cell (RBC) transfusions and other evidence from relevant trials (eg, Transfusion Requirements in Critical Care trial) or (2) compiled materials or recommendations from clinical practice guidelines, transfusion protocols or algorithms.
- Formal didactic group sessions.

- Adaptation of existing departmental or institutional rounds sessions or clinical staff meetings.

- One-on-one training sessions.

- Printed education materials distributed to participants or displayed in clinical settings (eg, graphics and posters).

\section{Protocol or algorithm}

Document with a comprehensive outline of steps and detailed criteria to follow for the treatment of specific patient groups or clinical setting; considered more rigid or specific than guidelines.

- Visual map or flow chart depicting clinical scenarios for management of anaemia.

- Clinical protocols to manage haemorrhaging.

- Patient blood management protocol with indications for RBC transfusions.

\section{Guideline}

Development and/or adoption of evidence-based clinical practice guidelines (ie, statements that include recommendations) intended to optimise care of patients.
- De novo institutional guidelines for RBC transfusions, appropriate management of anaemia or RBC/blood conservation.

- Adoption of guidelines developed by other institutions or expert clinical organisations.

\section{Computerised physician order entry and decision support}

Electronic order entry system for healthcare providers to directly enter medication, treatments or other requests for a patient; the system is programmed to prompt with alerts (eg, of guidelines) or other content to support clinical decisionmaking.

- Replacement of paper orders to electronic system that consolidates laboratory orders (eg, RBC orders) information with other patient chart information.

- Decision support algorithm incorporated into electronic order entry of RBC/blood products sent to blood banks or laboratories.

\section{Reminders}

Direct notification to healthcare providers of institutional clinical criteria, recommended use of medications or other treatments, or ordering processes.
- Paper forms provided when RBC/blood products are issued reminding healthcare providers of transfusion criteria and encouraging self-audit of practice.

- Alerts (electronic or by telephone) to healthcare provider when RBC transfusion orders placed outside of specified clinical indications (eg, higher haemoglobin level of patient) or existing guidelines.

Audit and feedback
$\begin{array}{ll}\text { Process to measure performance of healthcare providers } & \text { Transfusion practices were retrospectively audited and the } \\ \text { or patient outcome data over a specified period of time and } & \text { ordering healthcare providers were presented with his or her } \\ \text { to provide a summary (verbal or written) of this information } & \text { individual results in the context of the clinical department as } \\ \text { back to those healthcare providers in order to reach a } & \text { a whole and with other department faculty anonymised. } \\ \text { specified goal. } & \end{array}$

Audit approval
Medication, laboratory or other treatment orders are audited and for any not meeting prespecified institutional criteria, an approval is required before the order is approved.
RBC transfusions orders audited by blood bank or laboratory staff; those placed outside of recommended criteria were not issued and ordering healthcare providers were notified that requests were sent directly to departmental reviewers (eg, transfusion medicine specialists) for approval. 


\section{Table 1 Continued}

\section{Description of techniques}

Compulsory clinical and/or administrative directives for prescribing of medications, laboratory tests, other treatments.

\section{Examples from included studies}

- RBC ordering policy that enforce standard blood product ordering schedule and adherence to specific haemoglobin triggers.

\section{Paper order form}

Mandatory completion of a paper form to order specific medications, laboratory tests or other treatments.

\section{- Healthcare providers required to complete de novo} institutional paper order form for RBC transfusions and provide clinical rationale from prespecified list.

\section{Audit \\ Prospective or retrospective review of clinical performance or patient outcomes; the data are often electronically collected. \\ - Retrospective review of RBC transfusions orders outside of recommended clinical criteria (eg, haemoglobin trigger).}

\section{Financial incentive}

Provision of financial reward provided to individual or groups - Group-based financial rewards, scaled based on number of of healthcare providers on attainment of specific clinical performance goal. healthcare providers were issued if a $20 \%$ reduction in the mean number of RBC transfusions orders per patient-day compared with the previous year was obtained.

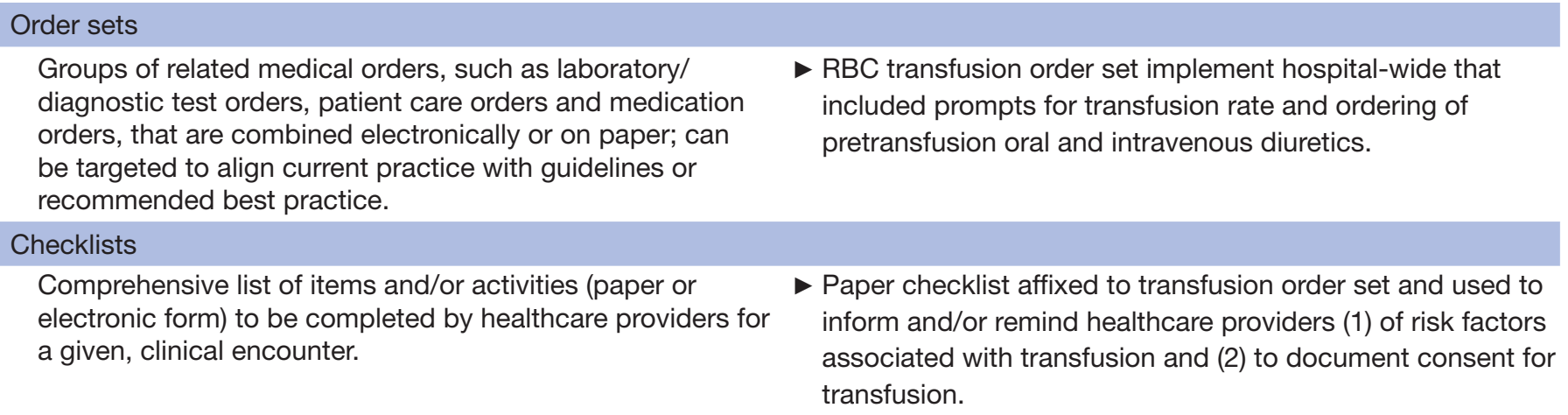

All 33 studies included in this analysis were non-randomised studies. A stratified analysis by non-randomised study design (online supplementary file 10) revealed high subgroup heterogeneity between the uncontrolled before and after studies $\left(\mathrm{I}^{2}=89.6 \%\right.$, Q-statistic $\left.\mathrm{p}=0.00\right)$. However, the variability between the two non-randomised trials was much lower $\left(\mathrm{I}^{2}=18.7 \%\right)$ and was likely due to chance alone (ie, not due to heterogeneity) (Q-statistic $\mathrm{p}=0.267$ ), suggesting that differences in study design might have contributed to some of the observed heterogeneity in the crude pooled estimate.

Further, stratification by intervention category revealed that differences in techniques across studies might have also contributed to study heterogeneity (figure 2; table 2). Among these interventions, the use of a protocol or algorithm (pooled OR 0.34 (95\% CI 0.19 to 0.60$) ; n=3$ ) and a multimodal intervention (pooled OR 0.73 (95\% CI 0.67 to 0.79$) ; n=20$ ) were associated with significantly decreased odds of patients being transfused. CPOE and decision support (OR 0.82 (95\% CI 0.69 to 0.9 ); $\mathrm{n}=1),{ }^{98}$ audit approval (OR 0.73 (95\% CI 0.70 to 0.78$) ; n=1)^{103}$ and policy interventions (OR 0.71 (95\% CI 0.53 to 0.95$)$; $\mathrm{n}=1)^{96}$ were also associated with decreases in the odds of transfusion; these point estimates, however, were derived from a single study in each subgroup(figure 2; table 2). No significant differences were observed between groups following the use of education (pooled OR $0.74(95 \%$ CI 0.44 to 1.24$) ; n=3$ ) and guidelines (pooled OR 0.17 $(95 \% \mathrm{CI} 0.01$ to 3.15$) ; \mathrm{n}=3)$ or reminders (OR $1.51(95 \%$ 0.86 to 2.66$) ; \mathrm{n}=1)$.

The impacts of behaviour modification interventions on secondary outcomes are summarised in table 2 and online supplementary files 11-15. An 'inappropriate' transfusion was defined by the included studies as a RBC transfusion initiated at a pretransfusion haemoglobin above $7-9 \mathrm{~g} / \mathrm{dL}$ for most, non-bleeding adult patients. 5557597076778990 100-102 Use of an intervention was associated with a decrease in the pooled odds of inappropriate transfusion (pooled OR 0.46 (95\% CI 0.36 to $0.59 ; \mathrm{I}^{2}=97.6 \%$, Q-statistic $\left.\mathrm{p}=0.00 ; \mathrm{n}=11\right)$. The mean RBC units transfused per patient (WMD: -0.35 units $(95 \%$ CI -0.38 to -0.32$) ; \mathrm{I}^{2}=99.9 \%$, Q-statistic $\mathrm{p}=0.00$; $\mathrm{n}=14)$ and mean patient LOS (WMD: -0.63 days $(95 \%$ CI -1.02 to -0.24$) ; \mathrm{I}^{2}=79.7 \%$, Q-statistic $\mathrm{p}=0.00 ; \mathrm{n}=9$ ) also decreased following the use of an intervention (table 2). The change in mean pretransfusion haemoglobin level was only examined among studies of multimodal interventions and was associated with a WMD of $-0.28 \mathrm{~g} / \mathrm{dL}$ 
( $95 \%$ CI -0.48 to $-0.08 ; \mathrm{I}^{2}=95.5 \%$, Q-statistic $\mathrm{p}=0.00$; $\mathrm{n}=5)$.

There was also significant heterogeneity in the pooled analyses of secondary outcomes $\left(\mathrm{I}^{2}\right.$ ranging from $57.4 \%$ to $99.9 \%$ ). It was unclear whether differences in interventions contributed to the heterogeneity, as stratification by intervention category left many subgroups with only one study; this precluded calculation of all subgroup $\mathrm{I}^{2}$ values (online supplementary files 11-15). Single modality interventions were associated with greater impacts on RBC usage, compared with multimodality interventions (table 2). Specifically, implementation of a guideline in one study resulted in the lowest odds of inappropriate transfusion (OR 0.07 (95\% CI 0.02 to 0.19 ) and the greatest decrease in mean RBC units transfused (WMD: -1.42 units $(95 \%$ CI -1.67 to -1.17$)) .{ }^{89}$ Another study examining a treatment algorithm reported the largest decrease in hospital LOS, however, there was marked variability in this estimate (WMD: -6.30 days (95\% CI-14.43 to 1.83 )). ${ }^{39}$ A significant increase in the odds of inappropriate transfusion (OR 1.74 (95\% CI 1.39 to 2.19)) was observed following audit and feedback in one study. ${ }^{101}$

There was no significant difference in the odds of in-hospital mortality (pooled OR 0.92 (95\% CI 0.84 to 1.02; $\mathrm{I}^{2}=64.8 \%$, Q-statistic $\mathrm{p}=0.00 ; \mathrm{n}=19$ ) (table 2). The stratified meta-analysis (by intervention type) suggested that the observed heterogeneity in the pooled estimate was likely attributed to the variability in interventions examined across studies (online supplementary file 15).

\section{Potential predictors of RBC usage}

Studies published on or after 1995, the year in which evidence of efficacy and safety of restrictive transfusion practices were first published, ${ }^{112}$ were included in the meta-regression. The year of publication, number of interventions, having a multimodal intervention, a single unit or clinical service setting, follow-up greater than 1 year, and the individual component interventions in a given study were not identified as significant predictors of RBC transfusion (online supplementary file 16).

\section{Publication bias}

Evidence for publication bias among included studies (open circle symbols) was indicated by the asymmetry in the funnel plot (figure 3) and Egger's regression test $(\mathrm{p}=0.001$ ). Ten studies were imputed using the trim-and-fill method (square with circle symbols) resulting in a pooled OR of 0.803 (95\% CI 0.663 to 0.972 ) for the primary outcome of patients being transfused. This suggests that studies of smaller patient sample size, reporting an increased likelihood of transfusion postintervention, may have been suppressed from publication.

\section{DISCUSSION}

Efforts to modify transfusion practices are not novel and have been described internationally for over four decades. We identified 84 studies, primarily non-randomised studies 


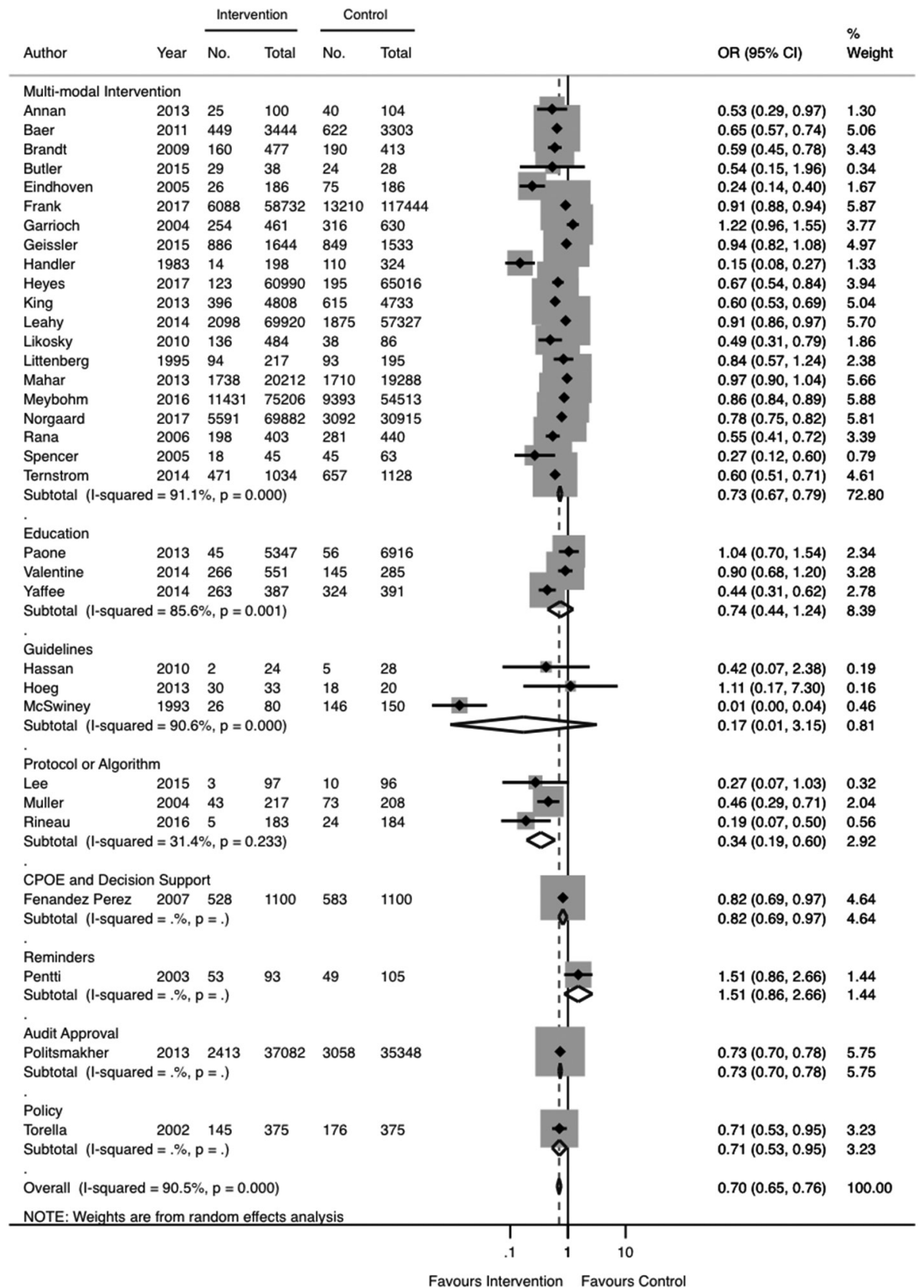

Figure 2 Forest plot of odds of patients being transfused, stratified by intervention. CPOE, computerised physician order entry.

of low to moderate quality, examining the impact of a behaviour modification intervention, compared with no intervention, on RBC transfusion practices. Among single modality interventions examined, nine categories were identified: education, protocol/algorithm, guidelines, CPOE and decision support, reminders, audit and feedback, audit approval, clinical policy, and prospective audit of transfusion practices. The majority of studies used multimodal interventions. Meta-analysis was permitted for a small subset of only non-randomised studies $(n=33)$. On average, the pooled odds of patients being transfused decreased by $30 \%$ (pooled OR 0.70 ; $95 \%$ CI 0.65 to 0.76 ) and patients received 0.35 fewer RBC units postintervention. In addition, the pooled average pretransfusion haemoglobin levels decreased by $0.28 \mathrm{~g} / \mathrm{dL}$ and the proportion of inappropriate transfusion (above a haemoglobin of $7-9 \mathrm{~g} / \mathrm{dL}$ ) decreased by approximately $54 \%$ (pooled OR $0.46 ; 95 \%$ CI 0.36 to 0.59 ). As expected, given the increasing body of evidence suggesting similar safety profiles between restrictive and liberal transfusion practices, ${ }^{13}$ there was no difference in the pooled odds of in-hospital mortality between intervention and comparator groups. Among all interventions examined, the protocol/algorithm and multimodal interventions were associated with the greatest decreases in the pooled odds of patients being transfused.

The present study represents the most up-to-date collection of published literature and the first meta-analysis of interventional studies in this field. Therefore, the 


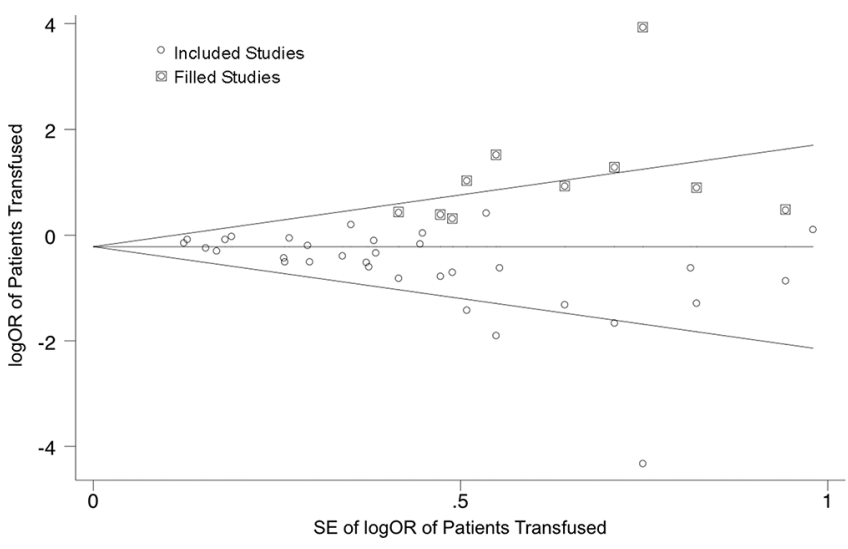

Figure 3 Filled funnel plot with pseudo 95\% Cls. The open circles represent the included studies and the squares with circles represent the imputed studies. The horizontal line represents the estimated measure of effect following the trimand-fill method and the diagonal lines forming the triangle region represent the pseudo $95 \% \mathrm{Cls}$.

analytical investigations performed in our study represent a substantial and novel contribution to the existing knowledge of how to achieve restricted RBC transfusion practices. Across all pooled estimates, we observed significant statistical heterogeneity, which was only partly attributed to the variability between interventions. Context-specific factors, not easily discernable from the available evidence, are also likely contributing to the observed heterogeneity among included studies. These may include variability in physician experience, clinical practice or flow, perceived ease of an intervention, and/or organisational capacity or receptivity for change. ${ }^{113}$ Work from the audit and feedback literature-which is among the most extensive in the area of behaviour modification interventions-also report variability in effect size of the intervention based on differences in baseline performance of the targeted behaviour, as well as nuances in delivery of the intervention (ie, how feedback is provided). ${ }^{114}$ Collectively, this information suggests that the decision to adopt a given intervention should, therefore, consider evidence of effectiveness and the factors related to the context and implementation. For instance, a labour-intensive intervention, such as a CPOE and decision support system, will be more feasible and efficient to implement in a setting with electronic ordering systems already in place, rather than in a one without. Explicit methodology to first identify relevant determinants to change and selection of an intervention(s) to address such determinants, such as through theory-based frameworks, might prove useful in tailoring an appropriate intervention to a given clinical setting. ${ }^{115} 116$

Our findings are consistent with the evidence from the broader knowledge translation literature. ${ }^{117}$ In one of the most comprehensive systematic reviews, Grimshaw et al ${ }^{117}$ identified over 200 studies examining the impact of interventions on a wide range of healthcare provider behaviours and settings. The authors identified a similar array of interventions (eg, education, audit and feedback, reminders) that were all were effective to varying degrees, and their observed effectiveness was not associated with the number of interventions implemented within a given study. ${ }^{117}$ The results of our meta-regression analysis further support that a multimodal intervention and the number of component interventions are not predictive of the impact of the interventions on the primary outcome.

Our results are also in line with the qualitative findings of previous systematic reviews of interventions to modify transfusion practices more broadly. ${ }^{16-18}$ Identified interventions were similarly found to be effective at reducing transfusion use, however, the previous reviews were unable to comment on their comparative effectiveness due to the dearth of direct comparisons between intervention types and reported heterogeneity among studies. ${ }^{1617}$ With our updated review of the literature, meta-analysis was feasible given the high prevalence of common study designs, as well as frequent reporting of our primary and secondary outcomes. While the comparator groups among included studies were also restricted to historical controls or standard of care, our stratified meta-analyses still enabled crude comparisons of effectiveness between interventions.

\section{Limitations}

The majority of included studies were non-randomised studies of low to moderate quality and susceptible to bias. For example, most studies employed an uncontrolled before and after study design and, in the absence of a concomitant control group, these studies were at high risk of bias due to both secular trends and maturation bias. ${ }^{118}$ Due to the lack of randomisation, such studies can also be susceptible to selection bias. ${ }^{23}$ In addition, we found limited to no reporting of participant characteristics and it is unclear whether and to what extent these characteristics led to confounding of the reported outcomes. The non-randomised studies were deemed to have moderate external validity, thus, generalisability of findings across all clinical settings and/or international healthcare systems is unclear.

Despite the large number of studies included in the systematic review, the primary outcome was only available for a minority of non-randomised studies $(n=33)$. Our stratified meta-analysis resulted in a very limited number of studies (or even one study) often of moderate quality, in many of the single modality subgroups. Taken together, these limited our ability to make inferences of comparative effectiveness across all intervention types and precluded our ability to perform further statistical techniques, such as network meta-analysis. ${ }^{119}$ While meta-regression was permitted for the primary outcome, similar analyses were underpowered for most secondary outcomes. ${ }^{120}$ Finally, the findings from our meta-analyses must be interpreted with caution given the evidence for publication bias. Previous reviews similarly suggested of publication bias among earlier included studies due to the tendency of outcomes to favour the intervention group. ${ }^{1617}$

Given such limitations of the non-randomised studies (particularly the uncontrolled before and after studies) 
and the meta-analytical efforts, it is difficult to state with certainty which intervention is the most effective at modifying RBC transfusion practice.

\section{Future research}

Further comparative effectiveness studies designed as large, high-quality RCTs are recommended to determine the effectiveness of the present interventions. However, the prevalence of low to moderate quality non-randomised studies included in this present review may indicate the logistical difficulty in evaluating these interventions through RCTs. As such, pragmatic trial designs may be considered to aid in balancing issues of feasibility with methodological rigour. ${ }^{121}$ Also, none of the included studies evaluated the effectiveness of a behaviour modification intervention to that of another behaviour modification intervention (of either single or multimodality). Such direct comparisons would aid in confirming effectiveness of interventions and help determine the comparative effectiveness of interventions. In the case of multimodal interventions, further research should also attempt to address which elements of the intervention are key to affecting the desired change. This information may better and more appropriately advise healthcare organisations seeking to implement the most effective behaviour modification intervention.

Lastly, we did not identify any studies that performed a concomitant economic evaluation. This information is critical to selecting an intervention that is also efficient within a given healthcare budget. Sixteen of the included studies did report of changes in healthcare costs, primarily cost savings in RBC usage, following either a single or multimodal intervention. ${ }^{30}$ 34-37 455761727580869098103104 Only two studies factored in the cost of implementing the intervention into their estimate. ${ }^{3498}$ Given the often costly, labour-intensive nature of many interventions, future cost-effectiveness studies should include the cost of implementation to determine whether true savings are realised from a given intervention.

\section{CONCLUSIONS}

We found a large body of literature evaluating the impact of behaviour modification interventions on RBC transfusion practices. The types of interventions are diverse, including single and multimodality interventions. The quality of included studies was low to moderate and the proportion of non-randomised studies was high $(\mathrm{n}=81)$. The protocol or algorithm and multimodal interventions were associated with statistically significant reductions in the pooled odds of RBC transfusion. These results must be interpreted with caution due to the prevalence of uncontrolled before and after studies, statistical heterogeneity, limited study sample size within intervention groups and evidence for publication bias. Given these limitations, further large, high-quality pragmatic trials would aid to confirm and directly compare effectiveness and cost-effectiveness of different types of behaviour modification interventions. This shift in the field from simply understanding 'does it work', towards investigating 'what works best' and 'at what cost' is required as healthcare organisations respond to meet the transfusion guideline recommendations.

Contributors Design of the study (LJJS, TWN, DLL and FMC); management of data (LJJS, FMC); analysis of data (LJJS, LED, KM, HMH and FMC); interpretation of the data (LJJS, TWN, HTS, DAZ and FMC); preparation of manuscript (LJJS, FMC); review of manuscript (LJJS, TWN, LED, KM, HMH, DLL, HTS, DAZ and FMC); approval of manuscript (LJJS, TWN, LED, KM, HMH, DLL, HTS, DAZ and FMC).

Funding LJJS is supported by an Alberta Innovates-Health Solutions (AlHS) Graduate Studentship Award (Record Number: 201500076).

Competing interests None declared.

Patient consent Not required.

Provenance and peer review Not commissioned; externally peer reviewed.

Data sharing statement All data generated or analysed during this study are included in this published article, its supplementary information files and the included reference articles (listed under Reference List).

Open Access This is an Open Access article distributed in accordance with the Creative Commons Attribution Non Commercial (CC BY-NC 4.0) license, which permits others to distribute, remix, adapt, build upon this work non-commercially, and license their derivative works on different terms, provided the original work is properly cited and the use is non-commercial. See: http://creativecommons.org/ licenses/by-nc/4.0/

(C) Article author(s) (or their employer(s) unless otherwise stated in the text of the article) 2018. All rights reserved. No commercial use is permitted unless otherwise expressly granted.

\section{REFERENCES}

1. Carson JL, Noveck H, Berlin JA, et al. Mortality and morbidity in patients with very low postoperative $\mathrm{Hb}$ levels who decline blood transfusion. Transfusion 2002;42:812-8.

2. Weiskopf RB, Beliaev AM, Shander A, et al. Addressing the unmet need of life-threatening anemia with hemoglobin-based oxygen carriers. Transfusion 2017;57:207-14.

3. Beliaev AM, Marshall RJ, Gordon M, et al. Clinical benefits and cost-effectiveness of allogeneic red-blood-cell transfusion in severe symptomatic anaemia. Vox Sang 2012;103:18-24.

4. Shander A, Hofmann A, Gombotz H, et al. Estimating the cost of blood: past, present, and future directions. Best Pract Res Clin Anaesthesiol 2007;21:271-89.

5. Delaney M, Wendel S, Bercovitz RS, et al. Transfusion reactions: prevention, diagnosis, and treatment. The Lancet 2016;388:2825-36.

6. Toy $P$, Gajic $O$, Bacchetti $P$, et al. Transfusion-related acute lung injury: incidence and risk factors. Blood 2012;119:1757-67.

7. Bolton-Maggs PH, Moon I. Assessment of UK practice for management of acute childhood idiopathic thrombocytopenic purpura against published guidelines. Lancet 1997;350:620-3.

8. Carson JL, Stanworth SJ, Roubinian N, et al. Transfusion thresholds and other strategies for guiding allogeneic red blood cell transfusion. Cochrane Database Syst Rev 2016;10:Cd002042.

9. Holst LB, Petersen MW, Haase N, et al. Restrictive versus liberal transfusion strategy for red blood cell transfusion: systematic review of randomised trials with meta-analysis and trial sequential analysis. BMJ 2015;350:h1354.

10. Docherty AB, O'Donnell R, Brunskill S, et al. Effect of restrictive versus liberal transfusion strategies on outcomes in patients with cardiovascular disease in a non-cardiac surgery setting: systematic review and meta-analysis. BMJ 2016;352:i1351.

11. Fominskiy E, Putzu A, Monaco F, et al. Liberal transfusion strategy improves survival in perioperative but not in critically ill patients. A meta-analysis of randomised trials. Br J Anaesth 2015;115:511-9.

12. Brunskill SJ, Millette SL, Shokoohi A, et al. Red blood cell transfusion for people undergoing hip fracture surgery. Cochrane Database Syst Rev 2015;28.

13. Carson JL, Guyatt G, Heddle NM, et al. Clinical practice guidelines from the AABB: red blood cell transfusion thresholds and storage. Jama 2016;316:2025-35. 
14. Grimshaw JM, Eccles MP, Lavis JN, et al. Knowledge translation of research findings. Implementation Science 2012;7:1.

15. Grimshaw JM, Eccles MP. Is evidence-based implementation of evidence-based care possible? Med J Aust 2004;180:S50.

16. Tinmouth A, Macdougall L, Fergusson D, et al. Reducing the amount of blood transfused: a systematic review of behavioral interventions to change physicians' transfusion practices. Arch Intern Med 2005;165:845-52.

17. Wilson K, MacDougall L, Fergusson D, et al. The effectiveness of interventions to reduce physician's levels of inappropriate transfusion: what can be learned from a systematic review of the literature. Transfusion 2002;42:1224-9.

18. Hibbs SP, Nielsen ND, Brunskill S, et al. The Impact of Electronic Decision Support on Transfusion Practice: A Systematic Review. Transfus Med Rev 2015;29:14-23.

19. Meybohm P, Richards T, Isbister J, et al. Patient Blood Management Bundles to Facilitate Implementation. Transfus Med Rev 2017;31:62-71.

20. Moher D, Shamseer L, Clarke M, et al. Preferred reporting items for systematic review and meta-analysis protocols (PRISMA-P) 2015 statement. Syst Rev 2015;4:1.

21. Soril LJJ, Sparling M, Gill S, et al. The effectiveness of behavioural interventions targeting inappropriate physician transfusion practices: a systematic review protocol: University of York: Centre for Reviews and Dissemination. 2015. cited 2016 November 25 http://www.crd.york.ac.uk/prospero/display_record.asp?ID= CRD42015024757 (accessed 25 Nov 2016).

22. Cook TD, Campbell DT. Quasi-experimentation: Design \& analysis issues for field settings. Chicago: Rand McNally, 1979.

23. Shadish WR, Cook TD, Campbell DT. Experimental and quasiexperimental designs for generalized causal inference: Wadsworth Cengage learning, 2002

24. Grimshaw J, et al. Experimental and quasi-experimental designs for evaluating guideline implementation strategies. Fam Pract 2000;17:11S-16.

25. Higgins JP, Altman DG, Gøtzsche PC, et al. The Cochrane Collaboration's tool for assessing risk of bias in randomised trials. BMJ 2011;343:d5928.

26. Downs $\mathrm{SH}$, Black N. The feasibility of creating a checklist for the assessment of the methodological quality both of randomised and non-randomised studies of health care interventions. Journal of Epidemiology \& Community Health 1998;52:377-84.

27. Higgins JP, Thompson SG. Quantifying heterogeneity in a metaanalysis. Stat Med 2002;21:1539-58.

28. Duval S, Tweedie R. Trim and fill: A simple funnel-plot-based method of testing and adjusting for publication bias in metaanalysis. Biometrics 2000;56:455-63.

29. Goodnough LT, Shieh L, Hadhazy E, et al. Improved blood utilization using real-time clinical decision support. Transfusion 2014;54:1358-65.

30. Goodnough LT, Maggio P, Hadhazy E, et al. Restrictive blood transfusion practices are associated with improved patient outcomes. Transfusion 2014;54(10 Pt 2):2753-9.

31. Rothschild JM, McGurk S, Honour M, et al. Assessment of education and computerized decision support interventions for improving transfusion practice. Transfusion 2007;47:228-39.

32. Handler S. Does continuing medical education affect medical care. A study of improved transfusion practices. Minn Med 1983;66:167.

33. Abelow A, Gafter-Gvili A, Tadmor B, et al. Educational interventions encouraging appropriate use of blood transfusions. Vox Sang 2017;112:150-5.

34. Frank SM, Thakkar RN, Podlasek SJ, et al. Implementing a Health System-wide Patient Blood Management Program with a Clinical Community Approach. Anesthesiology 2017;127:754-64.

35. Heyes J, Kelly PA, Monaghan K, et al. A single unit transfusion policy reduces red cell transfusions in general medical in-patients. QJM 2017;110:735-9.

36. Hicks CW, Liu J, Yang WW, et al. A comprehensive Choosing Wisely quality improvement initiative reduces unnecessary transfusions in an Academic Department of Surgery. Am J Surg 2017;214:571-6.

37. Madrigal E, Prajapati S, Avadhani V, et al. Adequacy of physician documentation and correlation with assessment of transfusion appropriateness: a follow-up study in the setting of prospective audits and patient blood management. Transfusion 2017;57:367-75

38. Norgaard A, Stensballe J, de Lichtenberg TH, et al. Three-year follow-up of implementation of evidence-based transfusion practice in a tertiary hospital. Vox Sang 2017;112:229-39.

39. Despotis GJ, Grishaber JE, Goodnough LT. The effect of an intraoperative treatment algorithm on physicians' transfusion practice in cardiac surgery. Transfusion 1994;34:290-6.
40. Soumerai SB, Salem-Schatz S, Avorn J, et al. A controlled trial of educational outreach to improve blood transfusion practice. JAMA 1993;270:961-6.

41. Alavi-Moghaddam M, Bardeh M, Alimohammadi $\mathrm{H}$, et al. Blood transfusion practice before and after implementation of type and screen protocol in emergency department of a university affiliated hospital in iran. Emerg Med Int 2014;316463.

42. Andreasen JJ, Sindby JE, Brocki BC, et al. Efforts to Change Transfusion Practice and Reduce Transfusion Rates Are Effective in Coronary Artery Bypass Surgery. J Cardiothorac Vasc Anesth 2012;26:545-9.

43. Annan E, Fless KG, Jasani N, et al. Red Blood Cell Transfusion Practices: Can High-Intensity ICU Staffing Stem the Tide? ICU Director 2013;4:11-14.

44. Ansari S, Szallasi A. Blood management by transfusion triggers: when less is more. Blood Transfus 2012;10:28-33.

45. Baer VL, Henry E, Lambert DK, et al. Implementing a program to improve compliance with neonatal intensive care unit transfusion guidelines was accompanied by a reduction in transfusion rate: a pre-post analysis within a multihospital health care system. Transfusion 2011;51:264-9.

46. Beaty CA, Haggerty KA, Moser MG, et al. Disclosure of physicianspecific behavior improves blood utilization protocol adherence in cardiac surgery. Ann Thorac Surg 2013;96:2168-74.

47. Brandis K, Richards B, Ghent A, et al. A strategy to reduce inappropriate red blood cell transfusion. Med $\mathrm{J}$ Aust 1994;160:721-2.

48. Brandt MM, Rubinfeld I, Jordan J, et al. Transfusion insurgency: practice change through education and evidence-based recommendations. Am J Surg 2009;197:279-83.

49. Butler CE, Noel S, Hibbs SP, et al. Implementation of a clinical decision support system improves compliance with restrictive transfusion policies in hematology patients. Transfusion 2015;55:1964-71.

50. Corwin HL, Theus JW, Cargile CS, et al. Red blood cell transfusion: Impact of an education program and a clinical guideline on transfusion practice. J Hosp Med 2014;9:745-9.

51. Gallagher-Swann M, Ingleby B, Cole C, et al. Improving transfusion practice: ongoing education and audit at two tertiary speciality hospitals in Western Australia. Transfus Med 2011;21:51-6.

52. Gardner RM, Christiansen PD, Tate KE, et al. Computerized continuous quality improvement methods used to optimize blood transfusions. Proc Annu Symp Comput Appl Med Care 1993:166-70.

53. Garrioch M, Sandbach J, Pirie E, et al. Reducing red cell transfusion by audit, education and a new guideline in a large teaching hospital. Transfus Med 2004;14:25-32.

54. Geissler RG, Kösters C, Franz D, et al. Utilisation of Blood Components in Trauma Surgery: A Single-Centre, Retrospective Analysis before and after the Implementation of an Educative PBM Initiative. Transfus Med Hemother 2015;42:83-9.

55. Gutsche JT, Kornfield ZN, Speck RM, et al. Impact of guideline implementation on transfusion practices in a surgical intensive care unit. J Cardiothorac Vasc Anesth 2013;27:1189-93.

56. Haldiman L, Zia H, Singh G. Improving appropriateness of blood utilization through prospective review of requests for blood products: the role of pathology residents as consultants. Lab Med 2014;45:264-71.

57. Harrison BT, Chen J, Der Vartanian C, et al. Improving red cell transfusion in the elective surgical setting: an improvement collaborative with evaluation. Vox Sang 2015;108:393-402.

58. King R, Michelman M, Curran V, et al. Patient-centered approach to ensuring appropriateness of care through blood management. South Med J 2013;106:362-8.

59. Leahy MF, Roberts H, Mukhtar SA, et al. A pragmatic approach to embedding patient blood management in a tertiary hospital. Transfusion 2014;54:1133-45.

60. Likosky DS, Surgenor SD, Dacey LJ, et al. Rationalising the treatment of anaemia in cardiac surgery: short and mid-term results from a local quality improvement initiative. BMJ Qual Saf 2010;19:392-8.

61. Littenberg B, Corwin H, Gettinger A, et al. A practice guideline and decision aid for blood transfusion. Immunohematology 1995;11:88-94.

62. Lucas RE, Oberli H. An audit to assess the impact of a strategy to reduce inappropriate red cell transfusions at Honiara Hospital. Trop Doct 1997;27:97-9.

63. Mahar FK, Moiz B, Khurshid M, et al. Implementation of Maximum Surgical Blood Ordering Schedule and an Improvement in Transfusion Practices of Surgeons subsequent to Intervention. Indian J Hematol Blood Transfus 2013;29:129-33. 
64. Marconi M, Almini D, Pizzi MN, et al. Quality assurance of clinical transfusion practice by implementation of the privilege of blood prescription and computerized prospective audit of blood requests. Transfus Med 1996;6:11-19.

65. Markel DC, Allen MW, Zappa NM. Can an arthroplasty registry help decrease transfusions in primary total joint replacement? a quality initiative. Clin Orthop Relat Res 2016;474:126-31.

66. McCrory MC, Strouse JJ, Takemoto CM, et al. Computerized physician order entry improves compliance with a manual exchange transfusion protocol in the pediatric intensive care unit. J Pediatr Hematol Oncol 2014;36:143-7.

67. Morrison JC, Sumrall DD, Chevalier SP, et al. The effect of provider education on blood utilization practices. Am J Obstet Gynecol 1993;169:1240-5.

68. Murphy DJ, Lyu PF, Gregg SR, et al. Using Incentives to Improve Resource Utilization: A Quasi-Experimental Evaluation of an ICU Quality Improvement Program. Crit Care Med 2016;44:162-70.

69. Oliver JC, Griffin RL, Hannon T, et al. The success of our patient blood management program depended on an institution-wide change in transfusion practices. Transfusion 2014;54(10 Pt 2):2617-24

70. Rana R, Afessa B, Keegan MT, et al. Evidence-based red cell transfusion in the critically ill: quality improvement using computerized physician order entry. Crit Care Med 2006;34:1892-7.

71. Rehm JP, Otto PS, West WW, et al. Hospital-wide educational program decreases red blood cell transfusions. J Surg Res 1998;75:183-6.

72. Rosen NR, Bates LH, Herod G. Transfusion therapy: improved patient care and resource utilization. Transfusion 1993;33:341-7.

73. Spencer J, Thomas S, Yardy G, et al. Are we overusing blood transfusing after elective joint replacement? - a simple method to reduce the use of a scarce resource. Ann $R$ Coll Surg Engl 2005;87:28-30.

74. Tavares MM, Diquattro PJ, Sweeney JD. Reduction in red blood cell transfusion associated with engagement of the ordering physician. Transfusion 2014;54(10pt2):2625-30.

75. Ternström L, Hyllner M, Backlund E, et al. A structured blood conservation programme reduces transfusions and costs in cardiac surgery. Interact Cardiovasc Thorac Surg 2014;19:788-94.

76. Vos J, Gumodoka B, van Asten HA, et al. Changes in blood transfusion practices after the introduction of consensus guidelines in Mwanza region, Tanzania. AIDS 1994;8:1135-40.

77. Yeh DD, Naraghi L, Larentzakis A, et al. Peer-to-peer physician feedback improves adherence to blood transfusion guidelines in the surgical intensive care unit. J Trauma Acute Care Surg 2015;79:65-70.

78. Yerrabothala S, Desrosiers KP, Szczepiorkowski ZM, et al. Significant reduction in red blood cell transfusions in a general hospital after successful implementation of a restrictive transfusion policy supported by prospective computerized order auditing. Transfusion 2014;54-2640-5.

79. Zelinka ES, Brevig J, McDonald J, et al. The perfusionist's role in a collaborative multidisciplinary approach to blood transfusion reduction in cardiac surgery. J Extra Corporeal Technol 2010;42:45-51.

80. Boral LI, Bernard A, Hjorth T, et al. How do I implement a more restrictive transfusion trigger of hemoglobin level of $7 \mathrm{~g} / \mathrm{dL}$ at my hospital? Transfusion 2015;55:937-45.

81. Hillman RS, Helbig S, Howes S, et al. The effect of an educational program on transfusion practices in a regional blood program. Transfusion 1979;19:153-7.

82. Joubert J, Joubert S, Raubenheimer J, et al. The long-term effects of training interventions on transfusion practice: a follow-up audit of red cell concentrate utilisation at Kimberley Hospital, South Africa. Transfus Apher Sci 2014;51:25-32.

83. Leão SC, Gomes MAB, Aragão MCdeA, et al. Practices for rational use of blood components in a universitary hospital. Revista da Associação Médica Brasileira 2015;61:355-61.

84. Paone G, Brewer R, Likosky DS, et al. Transfusion rate as a quality metric: is blood conservation a learnable skill? Ann Thorac Surg 2013;96:1279-86.

85. Valentine SL, Lightdale JR, Tran CM, et al. Assessment of hemoglobin threshold for packed RBC transfusion in a medicalsurgical PICU. Pediatr Crit Care Med 2014;15:e89-e94.

86. Yaffee DW, Smith DE, Ursomanno PA, et al. Management of blood transfusion in aortic valve surgery: impact of a blood conservation strategy. Ann Thorac Surg 2014;97:95-101.

87. Hoeg RT, Leinoe EB, Andersen P, et al. Measuring the impact of a restrictive transfusion guideline in patients with acute myeloid leukaemia. Vox Sang 2013;105:81-4.
88. Horowitz PE, Lorenzen CM, Rhydderch RD. Limiting the usage of blood products in cardiovascular surgery. Ann Saudi Med 1991;11:213-7.

89. McSwiney MM, O'Farrell D, Joshi GP, et al. Blood transfusion in total hip arthroplasty: guidelines to eliminate overtransfusion. Can $J$ Anaesth 1993;40:222-6.

90. Muller U, Exadaktylos A, Roeder C, et al. Effect of a flow chart on use of blood transfusions in primary total hip and knee replacement: prospective before and after study.[Erratum appears in BMJ. 2005 Feb;14(1):72], [Erratum appears in BMJ. 2004 Oct 9;329(7470):837] Bmj 2004;328:934-8.

91. Ciccocioppo A, Walker M, Taylor F, et al. Protocol management for patients presenting with lower Gl haemorrhage saves costs and maintains outcomes. ANZ J Surg 2011;81:451-5.

92. Lee QJ, Mak WP, Yeung ST, et al. Blood management protocol for total knee arthroplasty to reduce blood wastage and unnecessary transfusion. J Orthop Surg 2015;23:66-70.

93. Rineau E, Chaudet A, Chassier C, et al. Implementing a blood management protocol during the entire perioperative period allows a reduction in transfusion rate in major orthopedic surgery: a before-after study. Transfusion 2016;56:673-81.

94. Vrotsos E, Gonzalez B, Goldszer RC, et al. Improving blood transfusion practice by educational emphasis of the Blood Utilization Committee: experience of one hospital. Transfus Clin Biol 2015;22:1-4

95. Whitney G, Daves S, Hughes A, et al. Implementation of a transfusion algorithm to reduce blood product utilization in pediatric cardiac surgery. Pediatric Anesthesia 2013;23:639-46.

96. Torella F, Haynes SL, Bennett J, et al. Can hospital transfusion committees change transfusion practice? J $R$ Soc Med 2002:95:450-2.

97. Adams ES, Longhurst CA, Pageler N, et al. Computerized physician order entry with decision support decreases blood transfusions in children. Pediatrics 2011;127:e1112-e1119.

98. Pérez ERF, Winters JL, Gajic O. The addition of decision support into computerized physician order entry reduces red blood cell transfusion resource utilization in the intensive care unit. $A m \mathrm{~J}$ Hematol 2007;82:631-3.

99. McWilliams B, Triulzi DJ, Waters JH, et al. Trends in RBC ordering and use after implementing adaptive alerts in the electronic computerized physician order entry system. Am J Clin Pathol 2014;141:534-41

100. Pentti J, Syrjala M, Pettila V. Computerized quality assurance of decisions to transfuse blood components to critically ill patients. Acta Anaesthesiol Scand 2003;47:973-8.

101. Lewis CM, Monroe MM, Roberts DB, et al. An audit and feedback system for effective quality improvement in head and neck surgery: Can we become better surgeons? Cancer 2015:121:1581-7.

102. Tuckfield A, Haeusler MN, Grigg AP, et al. Reduction of inappropriate use of blood products by prospective monitoring of transfusion request forms. Med J Aust 1997;167:473-6.

103. Politsmakher A, Doddapaneni V, Seeratan R, et al. Effective reduction of blood product use in a community teaching hospital: when less is more. Am J Med 2013;126:894-902.

104. Larson EA, Thompson PA, Anderson ZK, et al. Decreasing the critical value of hemoglobin required for physician notification reduces the rate of blood transfusions. Int J Gen Med 2016;9:133-6.

105. Meybohm P, Herrmann E, Steinbicker AU, et al. Patient Blood Management is Associated With a Substantial Reduction of Red Blood Cell Utilization and Safe for Patient's Outcome: A Prospective, Multicenter Cohort Study With a Noninferiority Design. Ann Surg 2016;264:203-11.

106. Tseng E, Spradbrow J, Cao X, et al. An order set and checklist improve physician transfusion ordering practices to mitigate the risk of transfusion-associated circulatory overload. Transfus Med 2016;26:104-10.

107. Eindhoven GB, Diercks RL, Richardson FJ, et al. Adjusted transfusion triggers improve transfusion practice in orthopaedic surgery. Transfus Med 2005;15:13-18.

108. Lam HT, Schweitzer SO, Petz L, et al. Effectiveness of a prospective physician self-audit transfusion-monitoring system. Transfusion 1997;37:577-84.

109. Joyce KM, Byrne D, O'Connor P, et al. An evaluation of the use of deliberate practice and simulation to train interns in requesting blood products. Simul Healthc 2015;10:92-7.

110. Hassan NE, Winters J, Winterhalter K, et al. Effects of blood conservation on the incidence of anemia and transfusions in pediatric parapneumonic effusion: a hospitalist perspective. J Hosp Med 2010;5:410-3. 
111. Lam HT, Schweitzer SO, Petz L, et al. Are retrospective peer-review transfusion monitoring systems effective in reducing red blood cell utilization? Arch Pathol Lab Med 1996;120:810-6.

112. Hébert PC, Wells G, Marshall J, et al. Transfusion requirements in critical care: a pilot study. Jama 1995;273:1439-44.

113. Tinmouth A. Reducing the amount of blood transfused by changing clinicians' transfusion practices. Transfusion 2007;47:132S-6.

114. Ivers N, Jamtvedt G, Flottorp S, et al. Audit and feedback: effects on professional practice and healthcare outcomes. Cochrane Database Syst Rev 2012:CD000259.

115. Michie S, Johnston M, Abraham C, et al. Making psychological theory useful for implementing evidence based practice: a consensus approach. Qual Saf Health Care 2005;14:26-33.
116. Colquhoun HL, Squires JE, Kolehmainen N, et al. Methods for designing interventions to change healthcare professionals' behaviour: a systematic review. Implement Sci 2017;12:30.

117. Grimshaw JM, Thomas RE, MacLennan G, et al. Effectiveness and efficiency of guideline dissemination and implementation strategies. Health Technol Assess 2004;8:iii-iv.

118. Fergusson D, Hebert P, Shapiro S. The before/after study design in transfusion medicine: methodologic considerations. Transfus Med Rev 2002;16:296-303.

119. Mills EJ, Thorlund K, loannidis JP. Demystifying trial networks and network meta-analysis. BMJ 2013;346:f2914.

120. Higgins J, Green S. The Cochrane Collaboration. Cochrane Handbook for Systematic Reviews of Interventions Version 5.1.0. 2015. cited 2016 November 25 http://www.handbook.cochrane.org (accessed 25 Nov 2016).

121. Ford I, Norrie J. Pragmatic Trials. N Engl J Med 2016;375:454-63. 